\title{
Genetic Divergence Studies in Sesame (Sesamum indicum L.) Genotypes
}

\author{
B. Soundharya ${ }^{1 *}$, V. Hemalatha ${ }^{1}$, T. Shobha Rani ${ }^{2}$ and B. Edukondalu ${ }^{3}$ \\ ${ }^{1}$ Department of Genetics and Plant Breeding, College of Agriculture, PJTSAU, \\ Rajendranagar, Hyderabad, 500-030, Telangana, India \\ ${ }^{2}$ Plant Breeding, AICRP on Sesame, Sesame Research Scheme, RARS, Jagtial. \\ Karimnagar, Telangana, India \\ ${ }^{3}$ Department of Genetics and Plant Breeding, College of Agriculture, PJTSAU, \\ Jagtial, Karimnagar, Telangana, India \\ *Corresponding author
}

\section{A B S T R A C T}

\begin{tabular}{|c|c|}
\hline Keywo & $\begin{array}{l}\text { Sesame (Sesamum indicum } \mathrm{L} \text {.) }(2 \mathrm{n}=26) \text {, also known as Til or Gingelly, it is one of the } \\
\text { most important oilseed crop of tropical and temperate regions. Mahalonobis } \mathrm{D}^{2} \text { Statistics }\end{array}$ \\
\hline $\begin{array}{l}\text { Sesame, Genetic } \\
\text { Divergence, } \\
\text { D2 Statistics. }\end{array}$ & $\begin{array}{l}\text { was applied to access the divergence among the } 62 \text { sesame genotypes. The analysis of } \\
\text { variance revealed significant differences among the genotypes for all the trait studied. The } \\
62 \text { genotypes were grouped into } 6 \text { clusters where, cluster I was largest containing } 44\end{array}$ \\
\hline Articl & \\
\hline $\begin{array}{l}\text { Accepted: } \\
26 \text { August } 2017 \\
\text { Available Online: } \\
10 \text { September } 2017\end{array}$ & $\begin{array}{l}\text { ermplasm lines included in these clusters. Among the } 10 \text { quantitative traits studied the } \\
\text { nost important character contributing to the diversity was number of capsules per plant } \\
\text { ollowed by harvest index, number of branches per plant, } 1000 \text { seed weight, number of } \\
\text { eeds per capsule. }\end{array}$ \\
\hline
\end{tabular}

\section{Introduction}

Sesame (Sesamum indicum $\mathrm{L}).(2 \mathrm{n}=26)$, also known as Til or Gingelly, it is one of the most important oilseed crop of tropical and temperate regions. It is commonly known as "Queen of oilseeds" due to its resistance to oxidation and rancidity, also it plays an important role as an industrial food crop because of its high nutritional value. The seeds of sesame contains 40 to 63 per cent oil, which contains significant amount of oleic and linoleic acids (Abate and Mekbib, 2015).

Sesame is the most neglected oil seed crop grown on marginal lands under poor management resulting in low yields. Further, the poor yield is due to the non-availability of cultivars to suit the diverse agro climatic conditions. Hence development of improved high yielding cultivars adapted to local conditions has become top priority.

The objective of this research was identifying suitable diverse parents for hybridization, using the Mahalanobis $\mathrm{D}^{2}$ technique is a unique tool for identifying the degree of genetic divergence in a biological population and characters contributing to it, among 62 sesame genotypes using the $\mathrm{D}^{2}$ statistic. 
The experiment material consists of sixty two genetically diverse genotypes of sesame was carried out during kharif, 2015 at Regional Agricultural Research Station, Jagtial, Karimnagar, Telangana. Experiment material obtained from All India Coordinated Research Project on Sesame \& Niger (ICAR), JNKVV Campus, Jabalpur, Madhya Pradesh. The design adopted was Randomised Block Design (RBD) with three replications. Each genotype was raised in 4 rows of 4 metres long, adopting a spacing of $30 \mathrm{~cm}$ between rows and $10 \mathrm{~cm}$ between plants. Recommended package of practices were followed to raise good and healthy crop stand.

Five competitive plants were randomly selected for recording viz., plant height, number of branches per plant, number of capsules per plant, capsule length, number of seeds per capsule,1000 seed weight, seed yield per plant and harvest index. Days to $50 \%$ flowering, days to maturity were noted on plot basis.

The mean of five plants was subjected to statistical analysis. Wilk's criterion was used to test the significance of difference in mean values for all the ten characters. Genetic diversity was studied following Mahalanobis's (1936) $\mathrm{D}^{2}$ statistics and clustering of genotypes was done on the basis of $\mathrm{D}^{2}$ values according to Tocher's method as described by Rao (1952). Statistical analysis was done by WINDOSTAT program.

Based on $\mathrm{D}^{2}$ analysis, sixty two genotypes were grouped into 6 clusters. Cluster I was the largest comprising of forty four genotypes followed by clusters II with twelve genotypes, cluster VI with three genotypes, clusters III, IV and $\mathrm{V}$ were monogenotypic clusters, suggesting the existence of high degree of heterogeneity among the genotypes (Table 1).

The average intra and inter cluster $\mathrm{D}^{2}$ values are presented in table 2 and statistical distance among 62 genotypes. Intra cluster $\mathrm{D}^{2}$ values ranged from zero cluster (III, IV and V) to 59.13 (cluster VI). Maximum intra cluster distance was observed in cluster VI (59.13), followed by cluster II (42.25) and cluster I (38.31), indicating that some genetic divergence still existed among the genotypes within each of these clusters. Selection within such clusters might be executed based on maximum mean value for the desirable characters.

Maximum inter cluster distance was exhibited between cluster IV and VI (146.89) followed by cluster IV and V (141.37), cluster II and III (109.62), cluster II and V (102.01), cluster III and VI (99.60) and cluster III and IV (98.40).

The greater the distance between two clusters, the wider the genetic diversity among the genotypes of those clusters. Such highly divergent, high performing genotypes would be of great use in recombination breeding programme in order to get high heterotic recombinants. The lowest inter cluster divergence was noticed between cluster I and III (56.40), followed by cluster I and IV (58.67) indicating that the genotypes included in them were closely related.

It is assumed that maximum amount of heterosis will be manifested in cross combinations involving the parents belonging to most divergent clusters. But for a plant breeder, the objective is not only high heterosis but also other quality characters. Greater the distance between two clusters, wider the genetic diversity between the genotypes. Keeping this in view, it is indicated that hybridization between the genotypes SI-329 of cluster IV with Rajeshwari, Swetha Thil and RT-223 of cluster VI ; SI-329 of cluster IV with IS-167 of cluster V ; SI-983, DS-21, OSC-207, SI772, Pragati, IC-203966 of cluster II with SI775 of cluster III ; SI-983, DS-21, OSC-207, SI-772, Pragati, IC-203966 of cluster II with 
IS-167 of cluster V ; SI-775 of cluster III With Rajeshwari, Swetha Thil and RT-223 of cluster VI ; SI-775 of cluster III with SI-329 of cluster IV are expected to produce highly heterotic hybrids. The genotypes of these clusters may be used as parents in the crossing programme to generate breeding material with high diversity.

Table.1 Cluster classification of sesame genotypes (Tocher`s method)

\begin{tabular}{|c|c|c|}
\hline Cluster & $\begin{array}{l}\text { No. of } \\
\text { Genotypes }\end{array}$ & Genotypes \\
\hline I & 44 & $\begin{array}{l}\text { SI-205-1, DS-1, EC-269, RMT-166, EC-370934, SI-413-A, EC- } \\
\text { 377015, KMS-5-373, RMT-170, GT-2, RT-183, NIC-17325, } \\
\text { TKG-22, GT-10, NIC-16220, RMT-263, HT-2, NIC-8322, IC- } \\
\text { 204545, SI-199-2-84, EC-89111, SI-205-61, IS-167, IS-299A, } \\
\text { NIC-7921, ES-24, GT-4, EC-370840, RMT-236, ES-113-1-84, } \\
\text { RT-283, Prachi, RMT-215, NIC-17274, JLS-112, RT-313, } \\
\text { EC231-2-84, SI-1147, RMT-253, IC-204001, SI-44, Nirmala, } \\
\text { RMT-187 and DS-10. }\end{array}$ \\
\hline II & 12 & $\begin{array}{l}\text { SI-983, DS-21, OSC-207, SI-772, Pragati, IC-203966, NIC-8401, } \\
\text { ES-42-2-84, RMT-193, RT-54, ES-38and EC-370936. }\end{array}$ \\
\hline III & $\mathbf{1}$ & SI-775 \\
\hline IV & 1 & SI-329 \\
\hline $\mathbf{V}$ & $\mathbf{1}$ & IS-167 \\
\hline VI & 3 & Rajeshwari, Swetha Thil and RT-223 \\
\hline
\end{tabular}

Table.2 Intra and Inter clusters D value $\mathrm{D}^{2}$ value and extent of diversity among the clusters

\begin{tabular}{|l|l|l|l|l|l|l|}
\hline Clusters & Cluster I & Cluster II & Cluster III & Cluster IV & Cluster V & Cluster VI \\
\hline Cluster I & $\mathbf{6 . 1 9}$ & 8.45 & 7.51 & 7.66 & 7.85 & 9.86 \\
& $\mathbf{( 3 8 . 3 1 )}$ & $(71.40)$ & $(56.40)$ & $(58.67)$ & $(61.62)$ & $(96.23)$ \\
\hline Cluster II & & $\mathbf{6 . 5 0}$ & 10.47 & 9.04 & 10.10 & 9.41 \\
& & $\mathbf{( 4 2 . 2 5 )}$ & $(109.62)$ & $(81.72)$ & $(102.01)$ & $(88.54)$ \\
\hline Cluster III & & & $\mathbf{0 . 0 0}$ & 9.92 & 7.87 & 9.98 \\
& & & & $(98.40)$ & $(61.93)$ & $(99.60)$ \\
\hline Cluster IV & & & & $\mathbf{0 . 0 0}$ & 11.89 & 12.12 \\
& & & & & $(141.37)$ & $(146.89)$ \\
\hline Cluster V & & & & & $\mathbf{0 . 0 0}$ & 8.09 \\
& & & & & & $(65.44)$ \\
\hline Cluster VI & & & & & & $\mathbf{7 . 6 9}$ \\
& & & & & & \\
\hline
\end{tabular}


Table.3 Mean values of clusters for 10 characters in 62 sesame genotypes (Tocher's method)

\begin{tabular}{|c|c|c|c|c|c|c|}
\hline Clusters & \multirow[t]{2}{*}{ Cluster I } & \multirow[t]{2}{*}{ Cluster II } & \multirow[t]{2}{*}{ Cluster III } & \multirow[t]{2}{*}{ Cluster IV } & \multirow[t]{2}{*}{ Cluster V } & \multirow[t]{2}{*}{ Cluster VI } \\
\hline Character & & & & & & \\
\hline DF 50\% & 41.50 & 40.56 & 44.67 & 37.00 & 42.33 & 45.11 \\
\hline DM & 94.79 & 94.19 & 94.00 & 90.67 & 95.33 & 102.67 \\
\hline PH (cm) & 81.55 & 73.62 & 89.67 & 62.40 & 101.60 & 92.70 \\
\hline NBP & 3.26 & 4.01 & 4.20 & 5.27 & 2.80 & 4.80 \\
\hline NCP & 38.38 & 55.76 & 36.91 & 38.80 & 34.67 & 45.46 \\
\hline CL $(\mathrm{cm})$ & 2.59 & 2.55 & 2.59 & 2.50 & 2.52 & 3.00 \\
\hline NSC & 52.56 & 68.33 & 46.00 & 53.73 & 45.73 & 64.98 \\
\hline $1000 \mathrm{sw}(\mathrm{g})$ & 2.60 & 2.84 & 2.43 & 2.22 & 3.43 & 3.38 \\
\hline SYP(g) & 5.21 & 6.11 & 4.70 & 4.90 & 4.47 & 4.44 \\
\hline HI (\%) & 32.37 & 31.86 & 48.50 & 22.49 & 40.50 & 40.75 \\
\hline
\end{tabular}

The number of times that each of the ten characters appeared in first rank and its respective per cent contribution towards genetic divergence. The results showed that the contribution of number of capsules per plant was highest towards genetic divergence $(18.56 \%)$ by taking 351 times ranking first, followed by harvest index $(17.26 \%)$ by 326 times, number of branches per plant $(15.55$ $\%)$ by 294 times 1000 -seed weight (14.81\%) by 280 times, number of seeds per capsule (13.17\%) by 249 times, plant height $(8.09 \%)$ by taking 153 times, capsule length $(6.87 \%)$ by 130 times, days to maturity $(2.89 \%)$ by 55 times, days to $50 \%$ flowering $(1.80 \%)$ by 34 times and seed yield per plant $(1.00 \%)$ by 19 times to the genetic divergence in decreasing order. The results were in conformity with Solanki and Gupta (2001), Solanki and Gupta (2002), Sudhakar et al., (2006) and Chandramohan (2014) for number of capsules per plant, Manivannan and Nadarajan (1996) for plant height, Abate and Mekbib (2015) for plant height and harvest index, Kumaresan and Nadarajan (2003) for 1000-seed weight and Navale et al., (2001) for number of seeds per capsule.

The cluster means for each of ten characters are presented in table 3 . It can be seen from the data that considerable differences existed for all the characters under study. The data indicated that the cluster mean for days to 50 per cent flowering was highest in cluster VI (45.11) and the lowest in cluster IV (37.00). Days to maturity were exhibited highest and lowest means in cluster VI (102.67) and IV (90.67), respectively. Cluster $\mathrm{V}$ recorded highest mean for plant height $(101.60 \mathrm{~cm})$, while lowest was in cluster IV $(62.40 \mathrm{~cm})$. Cluster IV recorded the highest number of branches per plant (5.27) and the lowest was recorded in cluster $\mathrm{V}$ (2.80). The number of capsules per plant was highest in cluster II (55.76) and lowest in cluster V (34.67). Cluster VI showed highest capsule length (3.0 $\mathrm{cm})$ while in cluster IV it was low $(2.50 \mathrm{~cm})$. Cluster II and cluster V had maximum (68.33) and minimum (45.73) cluster means for number of seeds per capsule, respectively. Highest 1000-seed weight was recorded in cluster V (3.43 g) and lowest in cluster IV $(2.22 \mathrm{~g})$. Highest seed yield per plant was recorded in cluster II $(6.11 \mathrm{~g})$ and lowest in cluster VI (4.44 g) and cluster III expressed the highest harvest index $(48.50 \%)$ and the lowest was recorded in cluster IV $(22.49 \%)$. The results indicate that selection of genotypes with high cluster mean values for particular trait could be used in the hybridization programme for improvement of that character. 
The cluster II is having highest mean value for number of capsules per plant, number of seeds per capsule and seed yield per plant and cluster VI for days to $50 \%$ flowering, days to maturity, capsule length, cluster $\mathrm{V}$ for plant height and 1000-seed weight, cluster IV for number of branches per plant and cluster III for harvest index. The promising genotypes from these clusters with high mean values for different traits may be directly used for adaptation or may be used as parents in future hybridization, depending upon the objective of the breeding programme to derive superior transgressive segregants.

\section{References}

Abate, M., and Mekbib, F. 2015. Study on genetic divergence in low-altitude sesame (Sesamum indicum L.) germplasm of Ethiopia based on agro morphological traits. Journal of Advanced Studies in Agricultural, Biological and Environmental Sciences. 2(3): 78-90.

Chandramohan, Y., 2014. Variability and genetic divergence in sesame (Sesamum indicum L.). International Journal of Applied Biology and Pharmaceutical Technology. 5(3): 222-225.

Kumaresan, D., and Nadarajan, N. 2003. Genetic divergence analysis in sesame
(Sesamum indicum L.) Sesame and Safflower Newsletter. 18: 15-19.

Mahalanobis, P.C., 1936. On the Generalized distance in statistics. Proceedings of National Academy of Science India. 2: 49-55.

Manivannan, N., and Nandarajan, N. 1996. Genetic divergence in sesame. Madras Agricultural Journal. 82: 789-790.

Navale, P.A., Nimbalkar, C.A and Gandhi, H.I. 2001. Genetic divergence in sesame (Sesamum indicum L.). Journal of Maharashtra Agricultural Universities. 26(2): 144-146.

Rao, C.R., 1952. Advanced statistical methods in biometrical research. John Wiley and Sons INC., New York. 357363.

Solanki, Z.S., and Gupta, D. 2001. Variability and genetic divergence studies in sesame (Sesamum indicum L.). Sesame and Safflower Newsletter. 16: 28-31.

Solanki, Z.S., and Gupta, D. 2002. Genetic divergence for seed yield and other characters in sesame (Sesamum indicum L.). Journal of Oilseeds Research. 19(1): 35-37.

Sudhakar, N., Sridevi, O and Salimath, P.M. 2006. Genetic divergence in sesame (Sesamum indicum L.). Journal of Oilseeds Research. 23(2): 295-296.

\section{How to cite this article:}

Soundharya, B., V. Hemalatha, T. Shobha Rani and Edukondalu, B. 2017. Genetic Divergence Studies in Sesame (Sesamum indicum L.) Genotypes. Int.J.Curr.Microbiol.App.Sci. 6(9): 26152619. doi: https://doi.org/10.20546/ijcmas.2017.609.322 